exemplo, se cotejarmos a distribuição proporcional dos casos com a distribuição proporcional da população segundo cor da pele, poderemos observar que a proporção de casos por cor corresponde, aproximadamente, à distribuição populacional por cor, desautorizando, portanto, qualquer associação entre cor da pele e risco. Há entre os casos uma escassez relativa de pardos, "compensada" pela proporção dos casos com o quesito ignorado. Entretanto, como bem salientam os autores, essas quantidades não são imediatamente comparáveis porque no censo populacional a classificação de cor é feita pelo próprio indivíduo (autoclassificação), enquanto para os casos o quesito cor é preenchido pelo profissional de saúde. A alta proporção de não preenchimento da informação para os casos também prejudica qualquer análise (cerca de 15 a 23\%).

Em relação à escolaridade, conforme também assinalam os autores, a distribuição dos casos não corresponde à distribuição populacional havendo praticamente uma inversão: os casos se concentram nas camadas com maior escolaridade enquanto a população se concentra nas camadas com escolaridade fundamental ou sem escolaridade.

Portanto, se a análise dos dados fosse levada em consideração para a formulação das estratégias de comunicação social do programa e também para a orientação das ações preventivas não seria correto afirmar a ocorrência do fenômeno de "pauperização", uma vez que, os casos estão concentrados em grupos com maior escolaridade.

Assim, para verificar se a cor da pele em si é um determinante ou um marcador para a ocorrência de problemas de saúde é necessário controlar o efeito de confusão das variáveis sócio-econômicas, ainda que se saiba que estes controles matemáticos nunca logram isolar completamente os efeitos de cada variável.

A própria polêmica, referida pelos autores em torno de uma das peças publicitárias do programa no interior dos movimentos sociais, exemplifica a ausência de consenso acerca dos sentidos socialmente atribuídos às construções culturais e políticas em torno da saúde da população negra. Em outros momentos, a comunicação social adotou postura semelhante com outros grupos, ou seja, nem sempre houve consonância entre o perfil epidemiológico da doença e as mensagens publicitárias emanadas do programa.

A construção de um discurso social, cultural e político sobre a doença, mais ou menos descolado dos dados utilizados para descrever o perfil epidemiológico no âmbito populacional certamente têm conseqüências não apenas no âmbito cultural, social ou político, mas também para o próprio perfil epidemiológico. A mobilização política em torno de uma mitologia construída com indicadores propositalmente distorcidos, no início da epidemia, teve inegavelmente, papel importante para impulsionar as pesquisas, canalizar recursos, mobilizar as autoridades sanitárias para organizar serviços e programas de controle da AIDS. Por outro lado, essa mesma mitologia contribuiu para produzir classificações pretensamente científicas nas quais o fato de ser haitiano significava risco de infecção; discriminar grupos populacionais por seus comportamentos; estabelecer estereótipos com sua carga de preconceito e isolamento.

O reconhecimento da dívida que o país possui com a população negra, pelos anos de exploração e expropriação durante a escravidão e pela exclusão social após a "libertação", não deveria implicar o estabelecimento de associações espúrias entre cor de pele e problemas de saúde, ocultando toda sorte de determinantes sociais que o processo saúde-doença tem.

O compromisso sério com a saúde da população negra deve ser pautado por uma postura ética na condução de estudos que permitam esclarecer a parcela atribuível aos determinantes econômicos, sociais e políticos, aí incluídos os aspectos étnicos que vão além da cor da pele, na distribuição populacional dos problemas de saúde, sem recorrer a posturas paternalistas ou que reforcem a discriminação, com a construção cultural de brancos e negros como grupos estanques e perfeitamente distinguíveis em um país tradicionalmente marcado pela miscigenação e, no qual a discriminação por classe social sempre foi marcadamente mais forte.

Superar as desigualdades sociais em saúde no país é uma tarefa urgente, porém ela não deveria incluir a construção artificial de diferenças ou iniqüidades além das já existentes.

\section{Dora Chor}

Escola Nacional de Saúde Pública Sergio Arouca, Fundação

Oswaldo Cruz,

Rio de Janeiro, Brasil. dorinha@ensp.fiocruz.br
No Brasil, ao longo de décadas, a discussão sobre as desigualdades sócio-econômicas entre diferentes grupos raciais constituiu tema pouco abordado fora da literatura sociológica. Nos últimos anos, tornou-se assunto da sociedade brasileira, embora no âmbito da saúde pública, esta discussão ainda seja incipiente.

$\mathrm{O}$ debate a respeito do artigo de Peter Fry et al. é portanto da maior importância, por apresentar novas perguntas a respeito de tema complexo e polêmico. 
Em relação aos dados, duas afirmações são apresentadas pelos autores: (i) "Os dados epidemiológicos disponíveis não são suficientes para sustentar que existe associação específica entre população negra e AIDS no país"; (ii) "A análise dos dados oficiais da AIDS (...) contraria a tendência de crescimento de casos entre as populações mais vulneráveis socioeconomicamente ..." (pauperização da epidemia). Como detalharei a seguir, concordo apenas com a primeira afirmação.

A insuficiência de evidências empíricas da associação entre população negra e AIDS, no Brasil, deve-se às limitações dos dados. Na Tabela 1 , onde se encontra o número de casos registrados entre 2000 e 2005 (PN-DST/AIDS), segundo categorias de cor/raça, é possível levar em consideração apenas os dados de 2003, 2004 e 2005. Isso porque para 2000, 2001 e 2002 a proporção de informação ignorada no campo cor/raça é muito elevada e corresponde a $96 \%$, $88 \%$ e $59 \%$, respectivamente. É importante ressaltar que, em 2005, encontram-se apenas 10.745 casos, que representam $50 \%$ do total dos anos anteriores (provavelmente, a outra metade ainda não havia sido incorporada ao banco de dados). Assim, caso fosse conhecida, a distribuição da cor/raça poderia evidenciar perfil de desigualdade racial diferente daquele que é possível observar a partir dos casos registrados apenas em 2003, 2004 e 2005.

Embora tenham apontado corretamente a insuficiência dos dados disponíveis, é preciso relativizar algumas das limitações apontadas por Fry et al. em relação ao estudo da distribuição de desfechos de saúde segundo cor/raça. Os erros de medida são preocupação constante na classificação de grupos em estudos epidemiológicos. Além de tentar reduzi-los ao mínimo na fase de planejamento, outro grande desafio é imaginar de que forma esses erros podem contribuir para explicar os resultados. Por exemplo, qual é o impacto de diferentes tipos de classificação (raça por autoclassificação ou por profissionais de saúde), problema real citado pelos autores, nas conclusões a respeito da tendência temporal da AIDS? Ainda que não seja desejável, a utilização desses dois tipos de classificação estaria contribuindo para superestimar ou para subestimar a incidência da doença em determinada(s) categoria(s) de cor/raça? Como os erros de medida ou como os diferentes sistemas de classificação de cor/raça explicam o inaceitável excesso de mortes maternas entre as mulheres pretas ou pardas comparadas às brancas, de mesmo nível de escolaridade 1,2? Nesse caso, o acesso, uso e qualidade diferenciados dos serviços de saúde segundo cor/raça, além da posição sócio-econômica, devem ser investigados, enfrentando-se as limitações conceituais e metodológicas, mas também aprofundando o conhecimento sobre um dos desfechos exemplares das iniqüidades em saúde no Brasil.

Quanto aos problemas de preenchimento do campo raça/cor no SIM e no SINASC, este vem melhorando continuamente, de forma mais ou menos acelerada a depender do desfecho de saúde considerado ${ }^{3}$ (embora, como mostram Fry et al., menos aceleradamente no caso da AIDS). Considerando-se o ano de 2004, a proporção de raça ignorada foi de $9 \%$ e $10 \%$ no SIM (http:// tabnet.datasus.gov.br/cgi/sim/dados/ $\mathrm{cid} 10_{\text {_ }}$ indice.htm, acessadoem03/Set/2006) enoSINASC (http://tabnet.datasus.gov.br/cgi/sinasc/dados/ nov_indice.htm, acessado em 03/Set/2006), respectivamente, compatíveis portanto com investigações que incluam esta característica.

Quanto à segunda afirmação, relativa às tendências dos casos de AIDS, o aumento entre as populações mais vulneráveis do ponto de vista sócio-econômico foi evidenciado, entre 1987 e 1998, por vários autores nacionais, citados por Fry et al. 4,5. Segundo Bastos \& Szwarcwald 6 (p. 68), em um país como o Brasil, "estratos mais pobres e menos assistidos tornam-se mais vulneráveis à difusão dos agentes das doenças infecciosas por razões predominantemente biológicas (como pior imunidade), predominantemente sociais (menor capacidade de ter suas demandas atendidas, residência em locais com infra-estrutura precária), no mais das vezes por razões, simultaneamente, sociais e biológicas". Cabe mencionar, no caso específico da AIDS, que a seleção social no tratamento ${ }^{4}$ pode também contribuir para a oferta de serviços de pior qualidade para os grupos sociais menos privilegiados, favorecendo a disseminação da epidemia nos mesmos.

Apesar da limitação representada pelos casos com escolaridade ignorada (cerca de 20\%), o conteúdo das Tabelas 2 e 3 sugere aumento do número de casos no grupo que apresenta nível médio/superior e, com menor magnitude, diminuição de casos entre aqueles com escolaridade fundamental, como indicam Fry et al. No entanto, conclusões extraídas com base no número de casos, e sua distribuição proporcional, são insuficientes. Elas necessitam ser complementadas com investigação detalhada das taxas de incidência da doença em distintas regiões do país, estimadas segundo diferentes marcadores de nível sócio-econômico - por exemplo, a ocupação foi o marcador utilizado nas análises realizadas entre 1986 e 19974 - e também para os outros eixos de posição social que são o gênero e a raça. Esses procedimentos, necessários para analisar tendências temporais de qualquer desfecho, tornam-se ainda mais importantes nesse caso já que os mecanismos de explicação da possível 
reversão da tendência de crescimento de casos entre os grupos mais vulneráveis, do ponto de vista sócio-econômico, não são evidentes.

Em resumo, no caso da AIDS, ainda não é possível concluir que a incidência da doença vem aumentando entre pretos e pardos nem tampouco entre indivíduos com nível de escolaridade médio/superior, com base nos dados disponíveis e análises apresentadas para o período mais recente.

Ainda que conclusões prematuras a respeito da evolução da AIDS possam comprometer a efetividade da agenda de redução das desigualdades em saúde, já existem evidências suficientes de que a cor/raça é um dos determinantes de trajetórias sócio-econômicas desfavoráveis em nosso país 7,8,9, contribuindo para aumentar o risco de outros desfechos de saúde (e.g. mortalidade materna, ganho de peso, violência) $1,2,10,11$. Essas trajetórias são apenas parcialmente mensuradas pelos indicadores sócio-econômicos disponíveis, que podem ainda não ser equivalentes nos diferentes grupos raciais (e.g. mesmo nível de escolaridade de brancos, pretos e pardos não representa igual acesso a ocupações, renda e bens) 12. Além disso, já há evidências no Brasil 13 de que discriminação racial nos serviços de saúde piora a qualidade do tratamento para pretos e pardos, a exemplo do que tem sido reportado na literatura estrangeira 14,15 .

1. Centro de Vigilância Epidemiológica, Secretaria de Estado de Saúde do Rio de Janeiro. Relatório do Comitê Estadual de Prevenção e Controle da Morte Materna e Perinatal. Rio de Janeiro: Centro de Vigilância Epidemiológica, Secretaria de Estado de Saúde do Rio de Janeiro; 2005.

2. Costa JMBS, Lyra TM, Guimarães MJB, Santos SM, Oliveira CM, Mafra WS, et al. Desigualdades raciais na mortalidade materna em residentes no Recife, 2001-2004. In: Anais do 8o Congresso Brasileiro de Saúde Coletiva. Rio de Janeiro: ABRASCO; 2006.

3. Chor D, Lima CRA. Aspectos epidemiológicos das desigualdades raciais em saúde no Brasil. Cad Saúde Pública 2005; 21:1586-94.

4. Fonseca MG, Travassos C, Bastos FI, Silva NV, Szwarcwald CL. Distribuição social da AIDS no Brasil, segundo participação no mercado de trabalho, ocupação e status sócio-econômico dos casos de 1987 a 1998. Cad Saúde Pública 2003; 19:1351-63.

5. Fonseca MGP, Szwarcwald CL, Bastos FI. Análise sociodemográfica da epidemia de Aids no Brasil, 1989-1997. Rev Saúde Pública 2002; 36:678-85.

6. Bastos FI, Szwarcwald CL. AIDS e pauperização: principais conceitos e evidências empíricas. Cad Saúde Pública 2000; 16 Suppl 1:65-76.

7. Hasenbalg CA, Silva NV. Notes on racial and political inequality in Brazil. In: Hanchard M, editor. Racial politics in contemporary Brazil. Durham/ London: Duke University Press; 1999. p. 154-78.
8. Telles E. Racismo à brasileira: uma nova perspectiva sociológica. Rio de Janeiro: Editora RelumeDumará; 2003.

9. Barbosa MLO. As relações entre educação e raça no Brasil: um objeto em construção. In: Soares $S$, Beltrão KI, Barbosa MLO, Ferrão ME, organizadores. Os mecanismos de discriminação racial nas escolas brasileiras. Rio de Janeiro: Instituto de Pesquisa Econômica Aplicada; 2005. p. 5-19.

10. Chor D, Faerstein E, Kaplan GA, Lynch JW, Lopes CS. Association of weght change with ethnicity and life course socioeconomic position among Brazilian civil servants. Int J Epidemiol 2004; 33:100-6.

11. Batista LE, Escuder MML, Pereira JCR. A cor da morte: causas de óbito segundo características de raça no Estado de São Paulo, 1999 a 2001. Rev Saúde Pública 2004; 38:630-6.

12. Kaufman JS, Cooper RS, McGee DL. Socioeconomic status and health in blacks and whites: the problem of residual confounding and resiliency of race. Epidemiology 1997; 8:621-8.

13. Cabral ED, Caldas JEF, Cabral HAM. Influence of the patient's race on the dentist's decision to extract or retain a decayed tooth. Community Dent Oral Epidemiol 2005; 33:461-6.

14. Paradies Y. A systematic review of empirical research on self-reported racism and health. Int J Epidemiol 2006; 35:888-901.

15. Epstein AM, Weissman JS, Schneider EC, Gatsonis C, Leape LL, Piana RN. Race and gender disparities in rates of cardiac revascularization: do they reflect appropriate use of procedures or problems in quality of care? Med Care 2003; 41:1240-55.

\section{Mark Drew \\ Crosland \\ Guimarães}

Faculdade de Medicina,

Universidade Federal de Minas Gerais, Belo Horizonte, Brasil. drew@medicina.ufmg.br
Fry et al. apresentam argumentos políticos, históricos e epidemiológicos relativos à tendência da epidemia de AIDS no Brasil considerando a variável cor/raça. São arrazoados, bem elaborados divididos basicamente em dois itens: (i) interpretação de dados; e (ii) formulação de políticas públicas no Brasil. Gostaria de chamar a atenção principalmente para o primeiro aspecto. Apesar dos autores desenvolverem uma crítica às interpretações publicadas em boletins do PN-DST/AIDS, incorrem no mesmo erro ao tentarem estabelecer seu ponto de vista. Enfatizo um dos mais citados usos da epidemiologia, i.e., a geração e análise de dados que possam subsidiar a construção de indicadores norteadores da formulação de políticas públicas em saúde. A magnitude dos eventos em saúde, dada por informações descritivas de morbimortalidade, deveria apontar para prioridades a serem atendidas em programas de prevenção e/ou cuidados à saúde da população. No entanto, uma correta 